\title{
Aesthetic of Friction for Exercising Motivation: a Prototyping Journey
}

\author{
Alynne de Haan* \\ Industrial Design, Eindhoven \\ University of Technology, \\ the Netherlands, \\ a.a.d.haan@student.tue.nl
}

\author{
Daphne Menheere* \\ Industrial Design, Eindhoven \\ University of Technology, \\ the Netherlands, \\ d.s.menheere@tue.nl
}

\section{Steven Vos}

Industrial Design, Eindhoven

University of Technology, Fontys

University of Applied Sciences

Eindhoven, the Netherlands,

$$
\text { s.vos@tue.nl }
$$

${ }^{*}$ The first two authors contributed equally to this pictorial

Despite an intention to exercise, it remains a challenge for many people to establish a workout routine over a period of time. Amongst identified barriers and enablers to exercise, getting dressed for a workout is considered as one of the tipping points of actually going. Implementing the Aesthetic of Friction in this specific context, could imply the right course of action for the user, while it also allows freedom and encourages meaning-making. In this Research-through-Design project, we designed an interactive shrinking hanger, that implements these key principles, to encourage exercise motivation. We followed an iterative process focusing on the aesthetics of the interaction to find out how a careful consideration of the look and feel of an interactive artefact influences the acceptance of the implemented friction. We document the design process of this aesthetics of friction exemplar, and reflect on how to implement friction in design.

Authors Keywords

Aesthetic of Friction; exercising motivation; aesthetics of interaction; workout routine.

\section{CSS Concepts}

-Human-centered computing Human computer interaction (HCI) Interaction devices

Permission to make digital or hard copies of part or all of this work for personal or classroom use is granted without fee provided that copies are not made or distributed for profit or commercial advantage and that copies bear this notice and the full citation on the first page. Copyrights for third-party components of this work must be honored. For all other uses, contact the Owner/Author.

DIS '21, June 28-July 2, 2021, Virtual Event, USA

(C) 2021 Copyright is held by the owner/author(s).

ACM ISBN 978-1-4503-8476-6/21/06

https://doi.org/10.1145/3461778.3462079
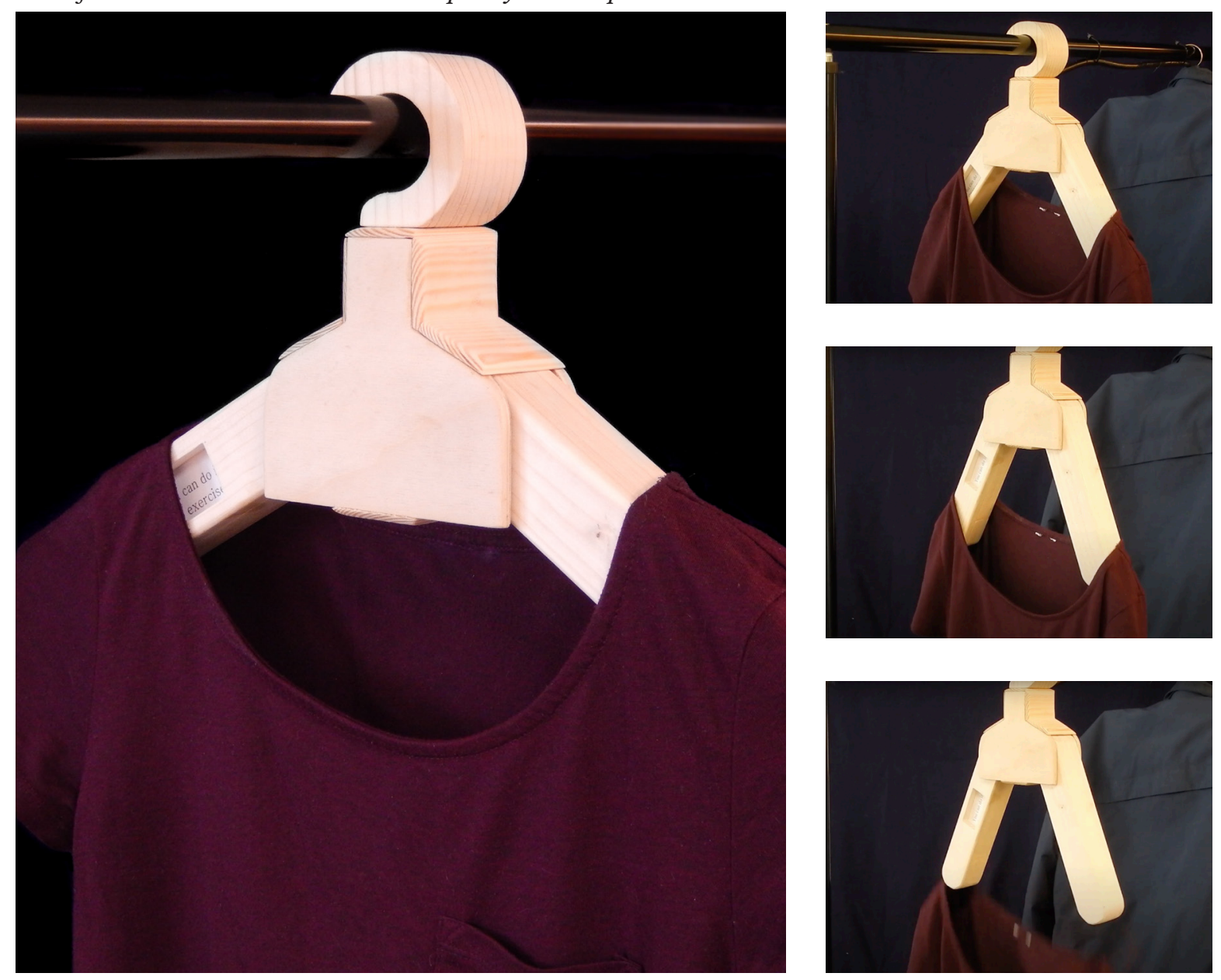

Meria is a clothing hanger that dismisses clothes when one does not go exercising as intended. 


\section{INTRODUCTION}

Many people have the intention to exercise regularly, yet the challenge remains to establish a workout routine over time, also known as the exercise intentionbehavior gap [22]. Previous research indicates barriers to exercise have an influence on this intentionbehavior gap $[15,17,21]$. Although these barriers can occur throughout the day, previous studies indicate preparational tasks before the actual session (e.g. preparing a sports bag, getting dressed) can already be perceived as a burden to exercise $[7,20]$. One study highlights that getting dressed before a workout can be considered as a tipping point of actually going [20] Intervening in this moment, by providing support or a nudge, might help people to overcome this barrier.

Nudging is not an unusual behavior change technique in design to change health behaviors, or to stimulate physical activity $[16,24]$. Nudging can take multiple forms, such as just-in-time prompts, removing certain options, enabling social comparisons or creating friction [2]. This last strategy, creating friction, is a way of confronting the user while aiming to be non-intrusive, acceptable and meaningful to the user while doing so $[2,5,10]$. Hassenzahl and Laschke (2015) introduced The Aesthetic of Friction (AoF), which include designs with an attitude also known as Pleasurable Troublemakers [5]. These troublemakers include frictional feedback that "attempts to disrupt routines and to imply alternative courses of action" (Laschke, 2015). Key principles of the AoF are, among others, that these designs are situated, they imply an alternative choice, provide freedom, and encourage meaning- making.

The AoF builds upon the theory of implementation intentions by Gollwitzer (1999). Traditional feedback systems do not always manage to fill the gap between what behavior people strive towards and the actual implementation [4]. Systems presenting actionable and situated opportunities for action such as the Pleasurable Troublemaker, are an opportunity to address this gap. They disrupt users' actions and nudge them to the desired behavior.
Situatedness. Pleasurable Troublemakers are often situated in the moment of choice. They use their intimate knowledge of the situation to create friction $[10,11]$. For example, Keymoment [14] is a keyholder that drops the bicycle keys the moment the user chooses to grab the car keys to take the car [14].

Alternative Choice. Designs following an AoF offer an alternative course of action in line with who someone would like to be [10]. The Intervator [6], is an overlay design on top of elevator buttons. When pressing the floor number, you need to go to, the Intervator presses the floor number of one level below, to promote physical activity. The visual information on the Intervator implies a different course of action than taking the elevator all the way up [6]

Freedom. The aim of Pleasurable Troublemakers is to alter the moment of choice, to not pressure someone into an action nor make it simpler for them [11] Threatening the freedom of the user, might result in a display of the behavior one is trying to avoid [10] Users always have the choice, and can even cheat the system.

Meaning-making. Another key element is the encouragement of a moment of reflection, especially when the user does not already share the same goal as the Pleasurable Troublemaker [5,6,10-14]. In ReMind [12], a calendar that drops agenda items when the user procrastinates, one is able to put the agenda item back up, even when not completed. However, doing so will create a moment of reflection for the user. Although it is easy to cheat the system, it is not easy to cheat on your own goals [12]

Besides adding friction, designs that implement the AoF have a careful balance between being friendly, yet troublesome, they are: "annoying, but in a nice way" [10]. The carefully designed interaction makes sure that the balance between being friendly while adding friction remains [14]. Enjoyment of the use of Pleasurable Troublemakers increases when there is a way to cheat the system. The design needs to be understanding of how difficult the change of behavior might be [5]. In Keymoment, the keys can easily be switched, or not picked up once they fall [14]. A Pleasurable Troublemaker should not be strict, but nonintrusive and ambiguous [5]. Another way to increase enjoyment is through making the product naive. The Never Hungry Caterpillar [5,10] creates awareness about energy use by depicting pain, however it is animal-like, naive and cute nature makes for the users to still find it appealing [5,10].

A few design examples illustrating key principles of AoF for behavior change are documented in the literature $[5,6,8,10,12,13]$. However, the focus of these contributions lays on the understanding of the experience and interaction rather than the design process. Little is known about how designers can actually explore material and interaction properties to design for the aesthetics of friction in a specific context. Laschke et al (2013) suggest that designing naive, understanding, and ambiguous interactive products is relatively unexplored and a better understanding on how to design for these is needed [12]

In this pictorial, we document the design of Meria, a troublemaking clothing hanger that dismisses clothes when one does not go exercising as planned. We followed an iterative process: we first explored the Aesthetics of Friction through sketching, conducted a survey $(\mathrm{N}=127)$ to investigate the 'right' level of friction, prototyped lo-fi iterations, designed Meria as an exemplar and conducted an in-situ user evaluation $(\mathrm{N}=1)$. In this process, we focused on the aesthetics of the interaction to find out how a careful consideration of the look and feel influences the acceptance of the implemented friction in Meria. The main contributions to the HCI and design community, of this paper are (1) a demonstration of how to apply the design paradigm, Aesthetic of Friction, throughout all stages of the design process, and (2) insights into the role of friction in design and behavior change. 


\section{EXPLORING THE AESTHETIC OF FRICTION THROUGH SKETCHES}

Inspired by the Pleasurable Troublemakers, we generated ideas by quickly sketching concepts. While reflecting on our ideas, we realized that multiple concepts were not situated in the moment of getting dressed. Since situatedness is a key element of AoF, we focused on the explorations that incorporated friction in the specific moment of getting dressed before a workout. In this phase of the design process we already uncovered multiple kinds of friction through introspection [26]. However, without experiencing the aesthetic features of the concept, it remains a matter of speculating how the movement, feel, sound or interaction influences the balance between aesthetics and friction. To get a first grasp on this balance, we grouped the different concepts in three levels depending on the intensity of the friction triggered. To further investigate this, we conducted

two parallel design activities: an online survey and lo-fi prototyping.

\section{The 'sticky door} handles is too is also influencin other moments in the user's life.

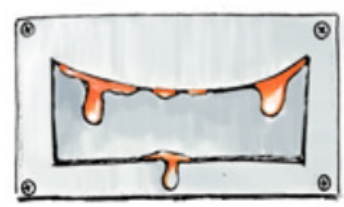

reward-based

too much friction
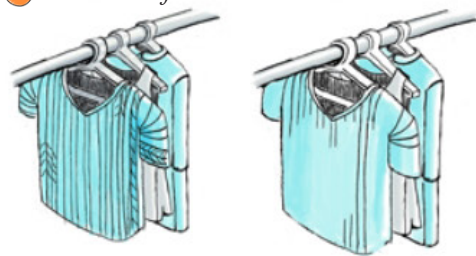

The 'fading patterns' is more based on pattern.

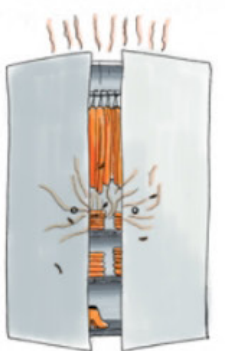

The 'smelling clothing'might
make the alternative course of action less

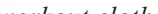
willing bad [9]

$$
\text { pattern. }
$$

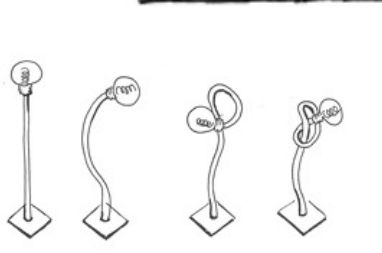

The "monochrome lights' in the clothing closet makes everything seem like one situated in the context of getting context of getting not very related to exercising.

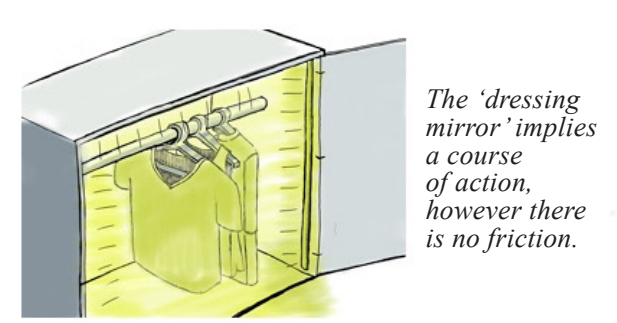

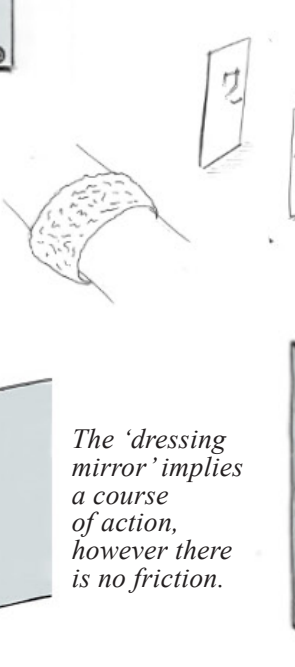
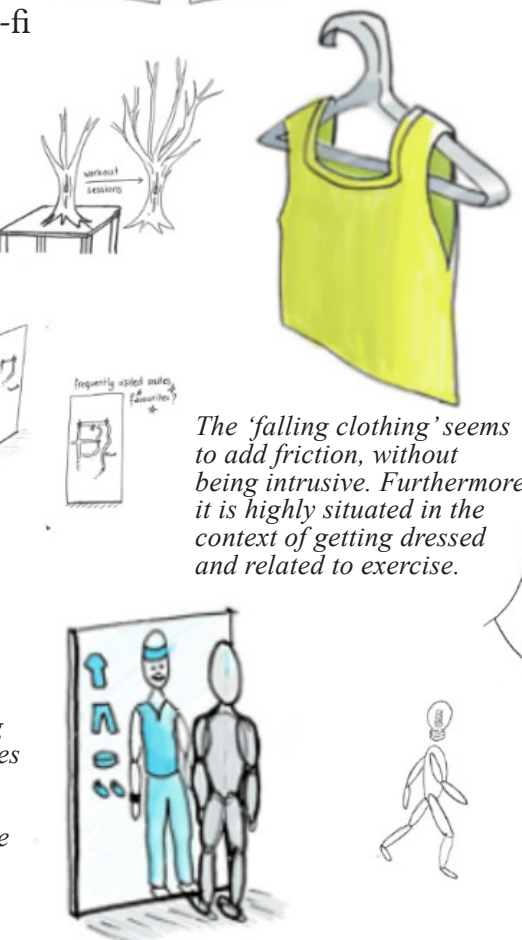
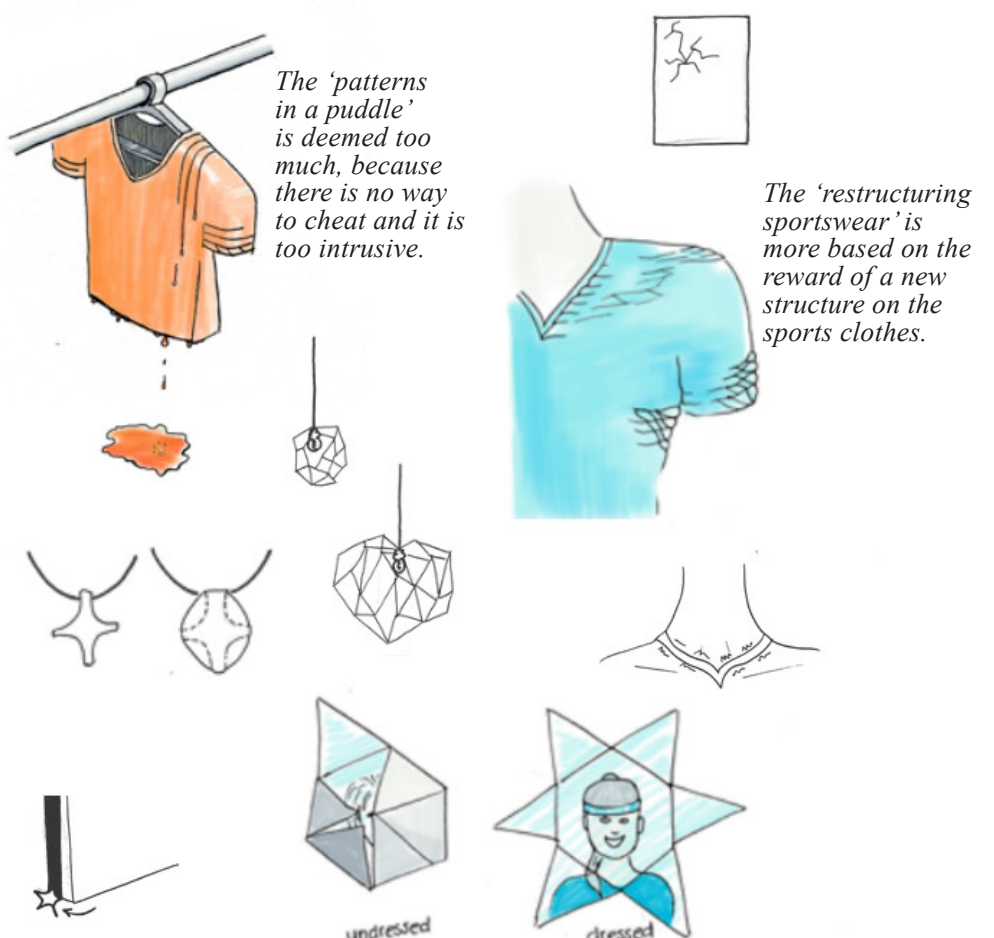

The 'unfolding mirror' creates friction by staying closed when not dressed. However it does not imply a course of action but demands it, by only providing a reward after getting dressed.
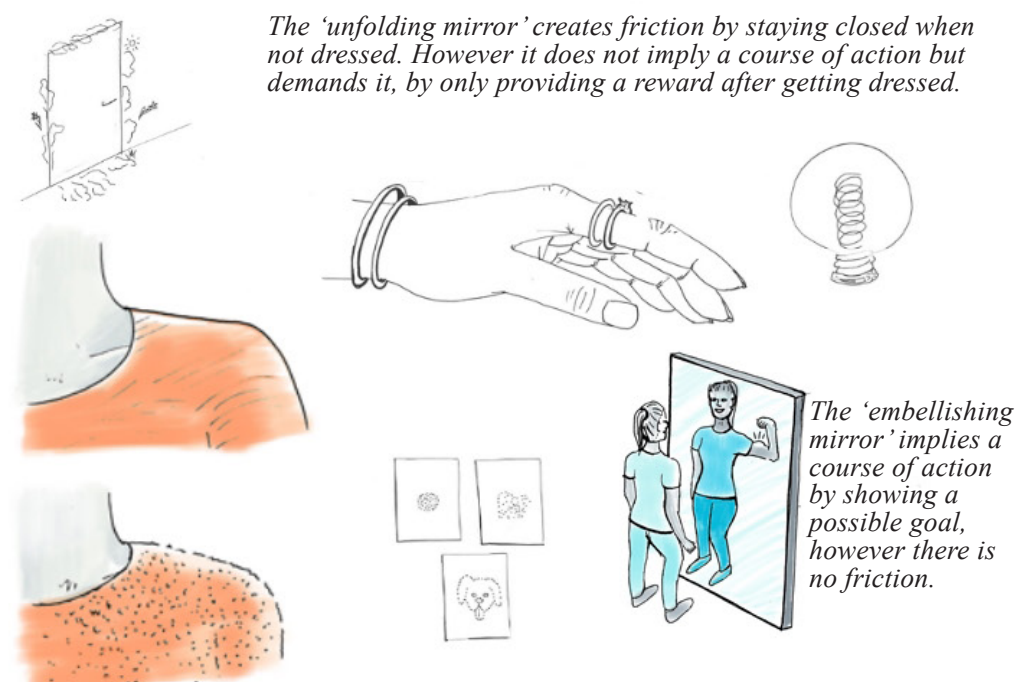


\section{USERS' PERSPECTIVES ON THE 'RIGHT' \\ LEVEL OF FRICTION}

To investigate what a right level of friction would be in our context, we selected three ideas, representing the three levels of friction conceptualized in our sketches, and translated them into short scenarios. We conducted an online survey among 127 participants. For each scenario, we asked the participants to choose a selection of five words based on the Product Reaction Cards [1] Following the characteristics of AoF, we envisioned that an AoF design should be associated with both positive and negative feelings. If a scenario is related to only negative words, the level of enjoyment is presumably too low, while a scenario solely linked to positive words does probably not incorporate enough friction to trigger behavior change. For the analysis, we looked at the combination of positive/negative words across all users.

\section{The Smelling Clothing}

1. You just washed your workout clothes
and put them back in your closet. They
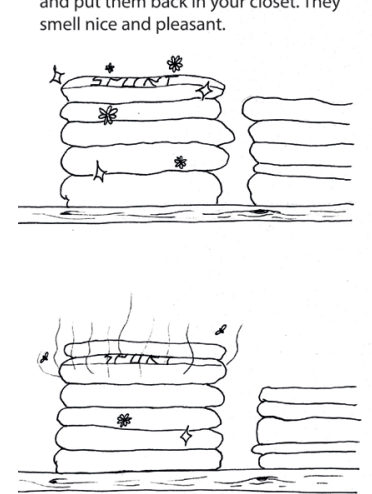

2. You aren't as active and you forget The clothes start to smell slightly unpleasant.

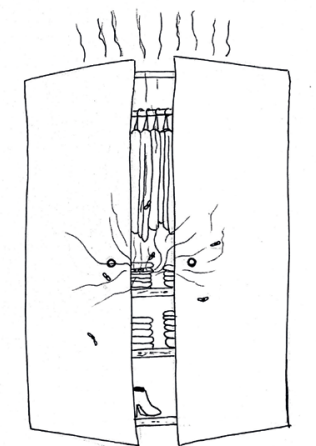

3. You have ignored your workout and clothes for so long that the unpleasant
smell starts to get out of your closet $Y_{0}$ can no longer ignore it.
The results of the survey were in line with our assumptions. While the Smelling Clothing was experienced as too frictional with only negative feelings as top-5 words (several respondents even self-describing it as "disgusting"), the Fading Patterns appeared too enjoyable with only positive feelings triggered. The Falling Clothing was more balanced, perceived as creative and innovative yet slightly annoying or frustrating

Reflecting upon the key principles of AoF, it appears that the Smelling Clothing does not provide a way to cheat the system: the design is not understanding and the clothing will start smelling, no matter if the user wants to avoid it. Also the smell might make the alternative course of action of going exercising harder to choose, since the clothes smell bad, there is a lack of freedom. Finally, it also impacts clothes laying near the exercise clothes, the friction extending thus way beyond the interaction with the AoF artefact.

\section{The Falling Clothing}
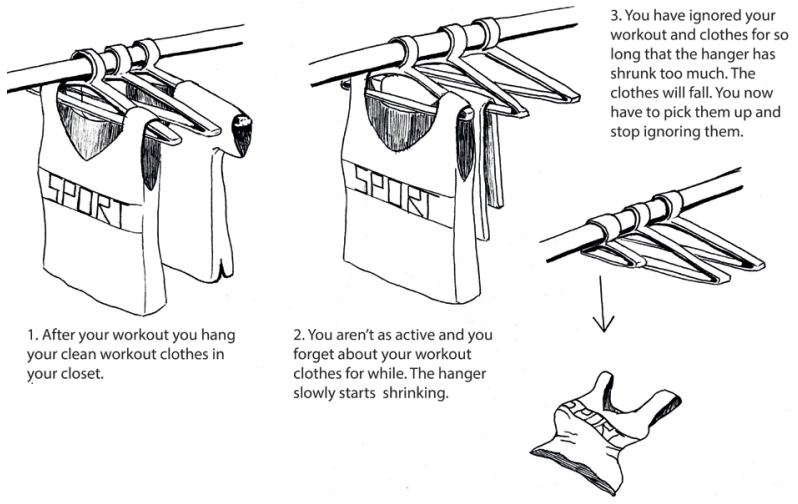

creative, annoying, frustrating, ineffective, innovative
The Fading Patterns concept was majorly associated with positive words. It does not really imply an alternative, and while acting in the context of getting dressed it is not situated in the moment of choice. In a classical design process, one might choose the concept that elicits the most positive responses, yet implementing an AoF stresses the importance of the balance between pleasure and troublemaking aspects, which was not the case for Fading Patterns.

The Falling Clothing elicited a mix of negative and positive feelings. While the negative words currently seemed slightly dominant, we believed that a strong focus on the aesthetics of the interaction on a physical prototype could bring more balance. At this conceptual stage, the aesthetic features are simply speculative and the user scenarios tend to highlight the friction. We decided to follow-up on this concept and explore ways to balance the aesthetics and the friction through making.

\section{The Fading Patterns}

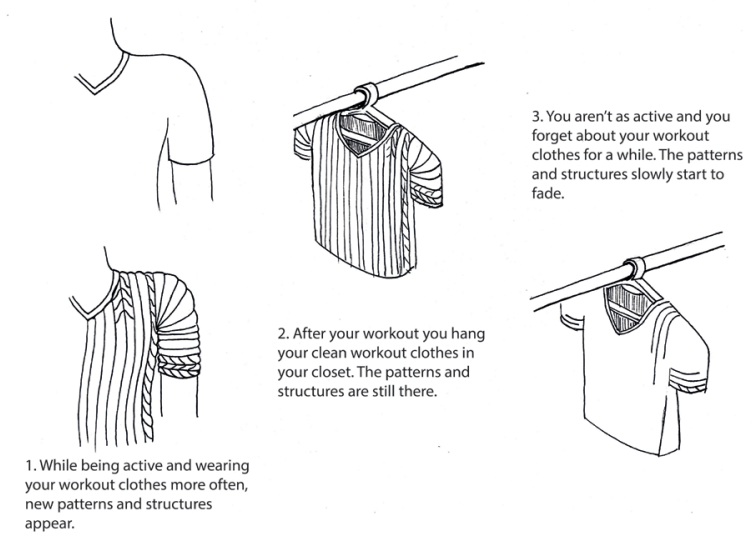

creative, entertaining, attractive, motivating, innovative 


\section{LO-FI PROTOTYPE}

In parallel with the survey, we prototyped two concepts from the sketches that we deemed 'interesting to explore'.

The Monochrome Lighting concept, in which all colors of clothing in the closet slowly seems to fade when someone does not go exercising, is inspired by the installation 'Room for one Colour' by Olafur Eliasson [3]. We used LED strips in an existing closet to prototype this effect. When the lighting emits one color only, it reduces the viewers' spectral range. Hence, the original colors of the clothing in the closet seemingly disappeared. It however became impossible to distinguish the sports outfit within the closet, which might be a barrier to the intended behavior.

The Falling Clothing concept lets the clothes fall to the ground when someone does not go exercising. In this prototype we integrated a motivational message, to try to get an even better balance for friction versus enjoyment. We fabricated new arms of $3 \mathrm{~mm}$ foam core on an old plastic hanger, and fastened these with a piece of string. While testing the prototype with clothes hanging on it, the clothing did not slip off easily. We realized that for clothing to actually slip off, the hanger needs to become even smaller. Another option is to change the angle of the arms of the hanger, creating a downward angle. The clothing also seemed to get stuck on the arms of the hanger, which thus needs to have a very smooth surface, for the clothes to be able to slide off. When comparing this lo-fi prototype with other hangers, we realized that the aesthetics of the hanger, both its look and feel, did not fit, and rather stood out instead of blending in. While clothing hangers come in many forms and materials, our aim is to research material properties that would support the intended AoF.

While both concepts seemed intriguing to explore further, the Monochrome Lighting seemed too intrusive. As illustrated in our survey, concepts that extend the friction beyond the interaction with the AoF artefact itself might not be accepted. Although being both situated in the 'getting dressed moment', the Falling Clothing concept more closely related to exercising and we thus iterated further on it as part of our research process.
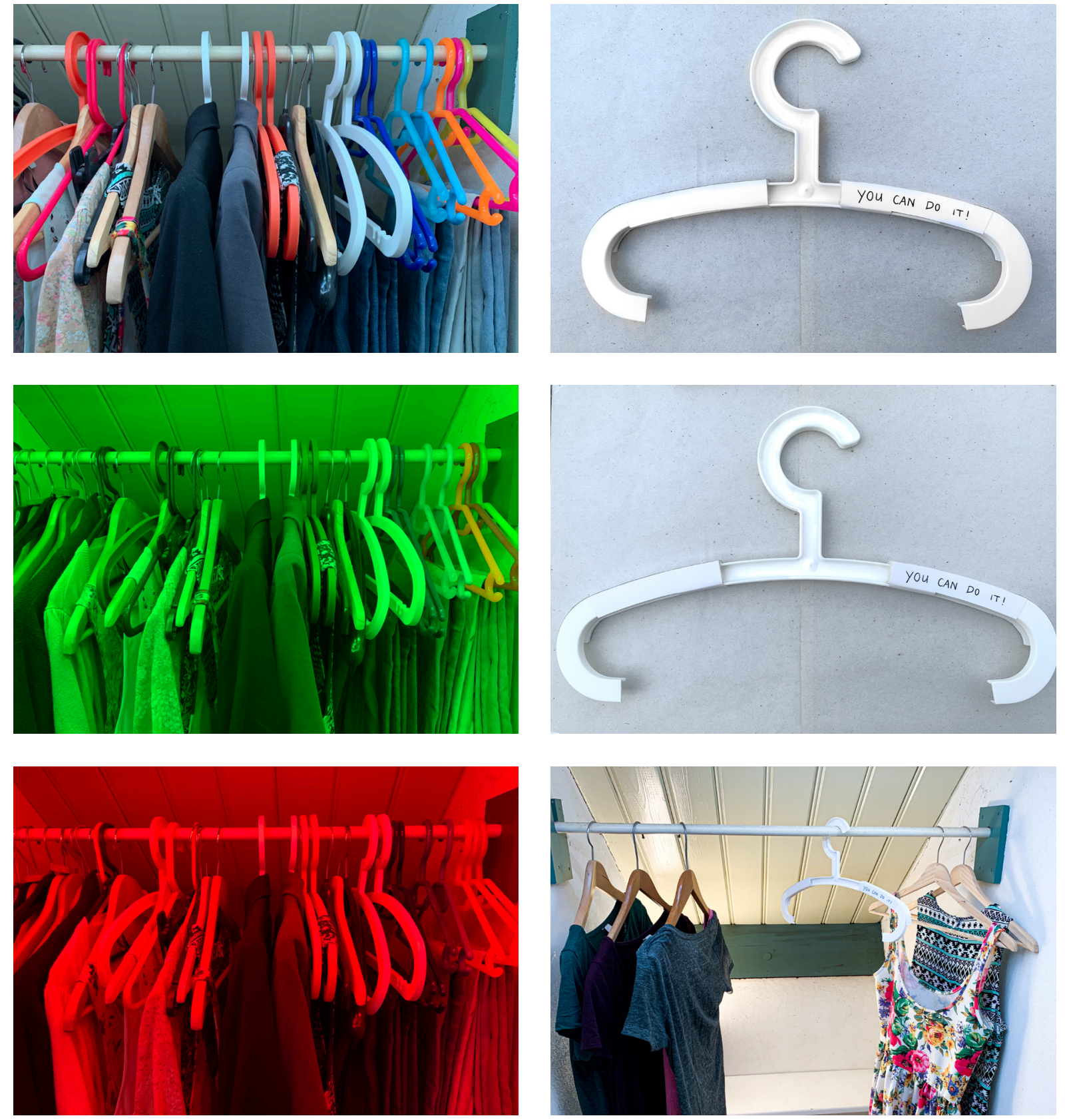


\section{UNDERLYING DESIGN PRINCIPLES}

In the following section, we will elaborate upon the different design iterations and the aesthetics through making of the Falling Clothing, and how we think these iterations will influence the balance between friction and friendly nudging.

\section{Materiality}

Based on the insights of the first iteration, we made a second version of the concept with cardboard, in order to explore the movement of the arms and the space needed for the components. The arms of the hanger are designed at an angle of 25 degree downwards as a starting point, inspired by classical hangers for a more seamless integration in an existing closet. The arms move approximately 65 degrees downwards, in order to come to 90 degrees 'shrunk' position. This enables clothes to slide off more easily.

A third prototype was made of scrap wood to explore aesthetical properties, by changing the $2 \mathrm{D}$ shape to a $3 \mathrm{D}$ shape. We wanted the hanger to resemble interaction
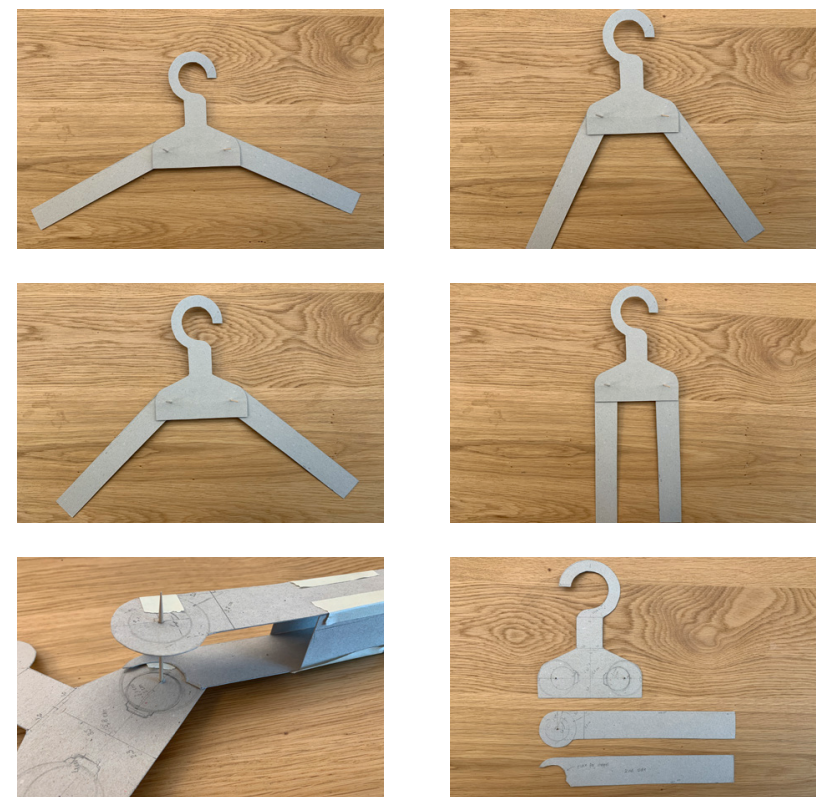

characteristics of a classical hanger, with non-intrusive aesthetical features, since non-intrusiveness is an important element in the AoF.

The arms are made of a stacking of multiple layers of wood, but this wood was tough and hard to mold in a nice round and smooth way which seemed important for an inviting AoF design. Consequently, we chose spruce for our final design, which is light and easy to mold. To gain that seamless finish we are after, we went for a solid wood and only made the part of the components hollow. Spruce board was used to close off the edges of the hanger. To give the hanger a calm demeanor, we kept the natural light wood color of spruce. We took care to sand the arms of the hanger in a round shape. Not only is this important to get the surface smooth for the clothes to slide off easily, it is also important according to the AoF principles that the design looks friendly and inviting as a way to make the friction more bearable. We want the hanger to feel soft when taking it off, and sanded wood often gives this feeling.

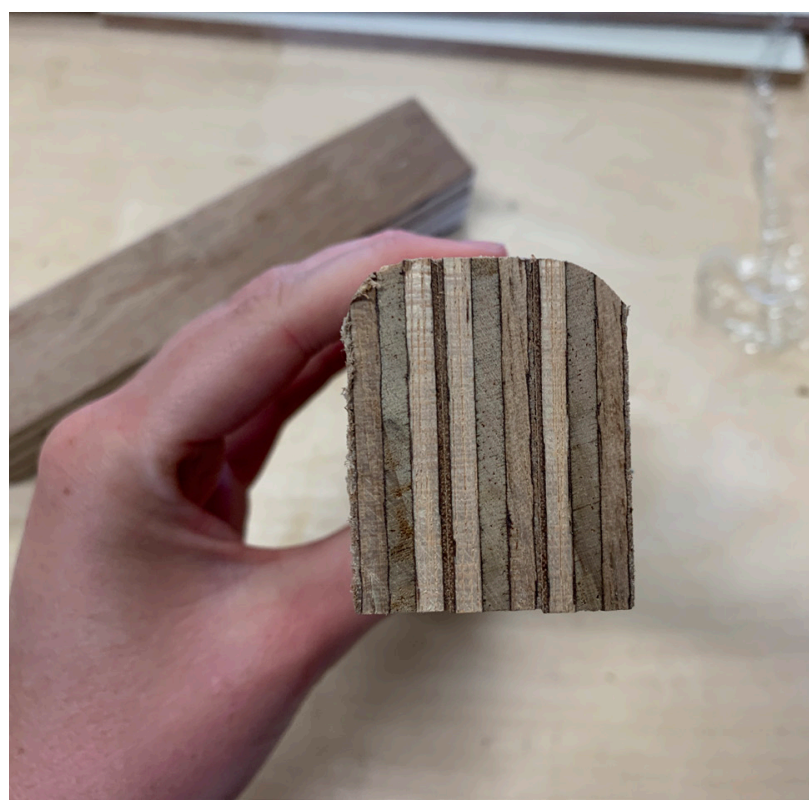

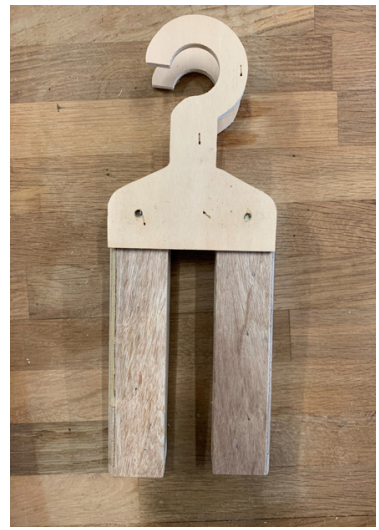
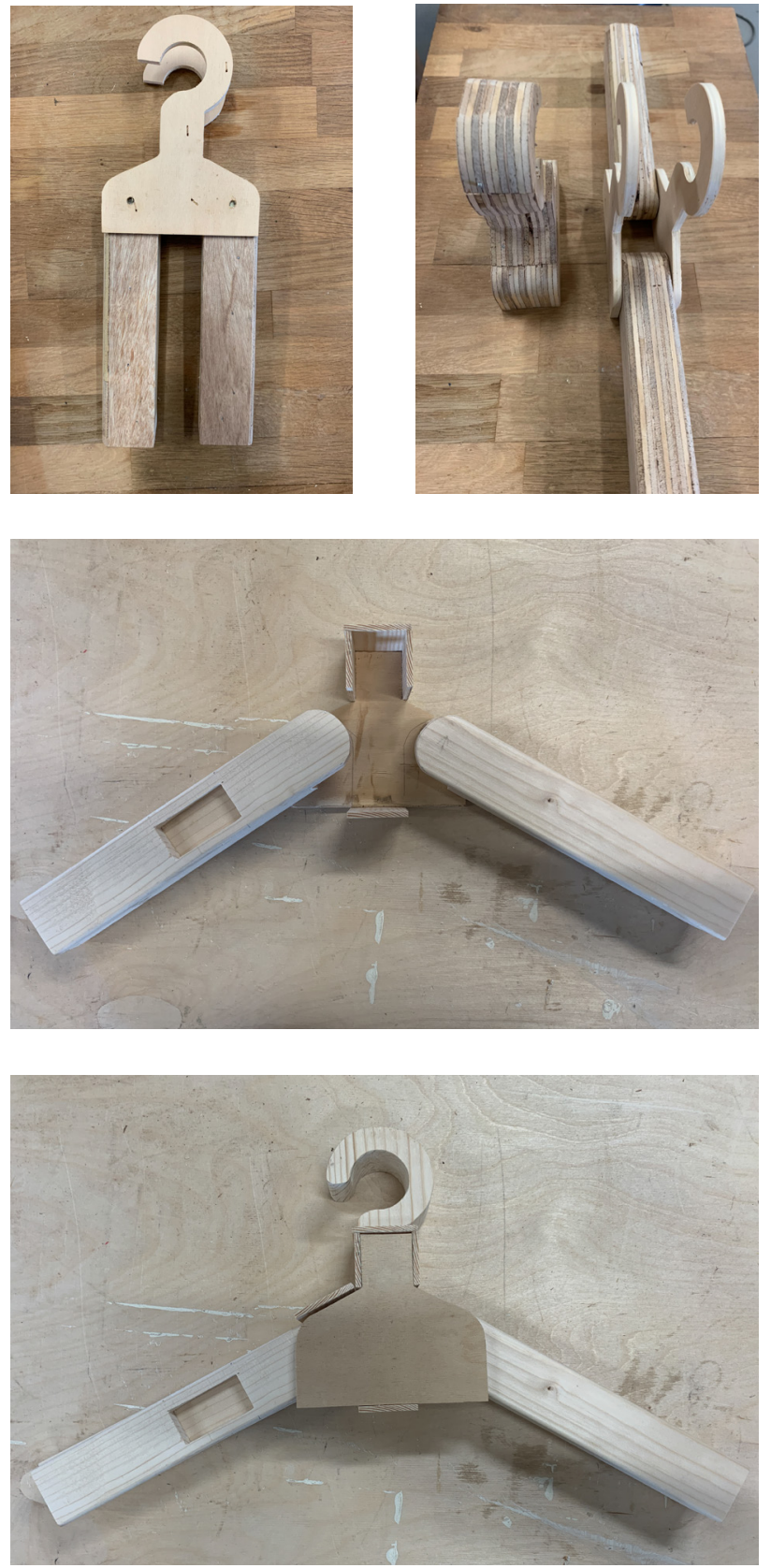


\section{Movement}

To facilitate the movement of the arms we chose two small stepper motors. These motors hardly produce any sound and have the ability to move in tiny steps. The hanger should be non-intrusive, and thus should not be heard outside the closet. Since we chose very small stepper motors to limit the sound, we needed a way to increase their torque to hold up the weight of the arms and clothing. We built a gear box of stainless steel inside the hanger. Every stepper had a metal cogwheel of 10 teeth on its axil. Per arm three plastic compound cogwheels were added with a 1:5 gear ratio per cogwheel. Making the total ratio stepper motor to arm 1:125. This ratio caused the arms to move really slowly, at a pace almost invisible at first glance taking a few days to fully shrink. Through this, we aim for a gentle reminder at first, which is not supposed to cause high stress yet. The intended annoyance is triggered later, when the clothing almost falls off. This adds to the experience of anticipation and the user having an idea of how much time is left and maybe 'they can beat the hanger to it'. If it would fall off suddenly, the act of surprise and not being able to control it, would take over. While the slow movement of the interaction contributes to the enjoyment and the ability of being in control of the decision-making process, both key elements of AoF.

When there is no clothing anymore, the arms move up in about 2 minutes. We wanted to incorporate an intentional delay when going back to its original shape again. In this waiting time, we aim to create a reflection moment before being able to hang the clothes back. Although this might seem fast as compared to the time it needs to shrink, more than two minutes of waiting might be considered too long, risking the user to give up and not use the hanger anymore. This slow movement was also deemed important to avoid dissonance with the overall behavior of the hanger.

\section{Interaction}

In the first prototype, when the arms of the hanger slide, the motivational text moves towards the middle, slowly appearing over time. However, we intended to keep the text hidden until the user takes the clothes off the hanger. The text should thus either stay in one place, or only appear when the user interacts with the hanger. For this iteration, we choose to embed the motivational text within the wood of the hanger. Only when the user interacts with the hanger, they will be able to see it because of the depth it is placed. We chose the modality of text, since it is non-intrusive and can be discovered upon interacting with the hanger. Ideally, the text should not be static but change regularly in order to sustain the feeling of discovery and reward. A future prototype could use an e-ink screen for that purpose.
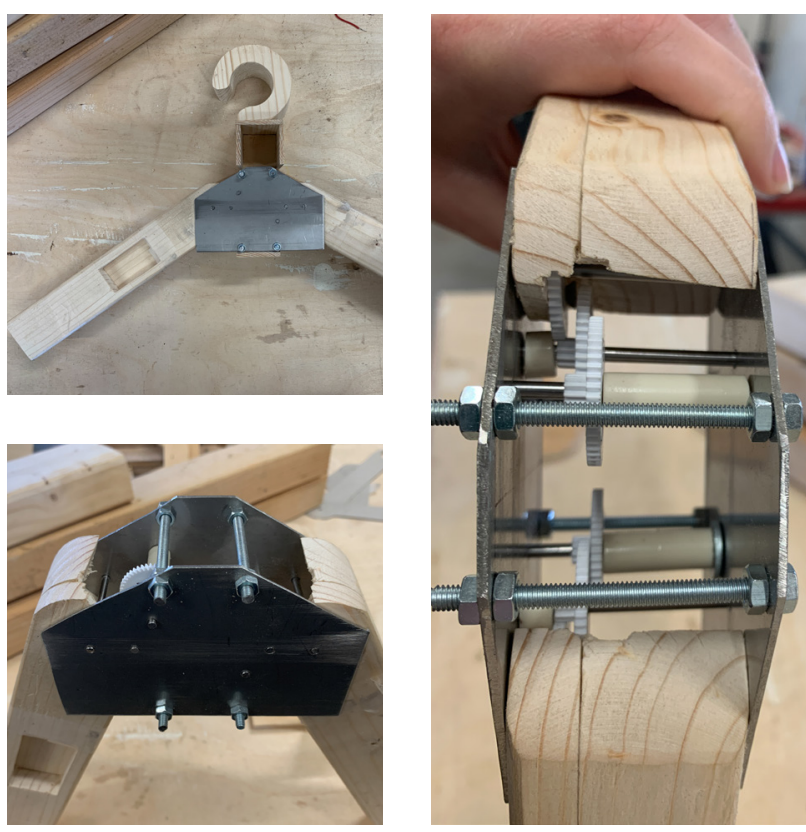
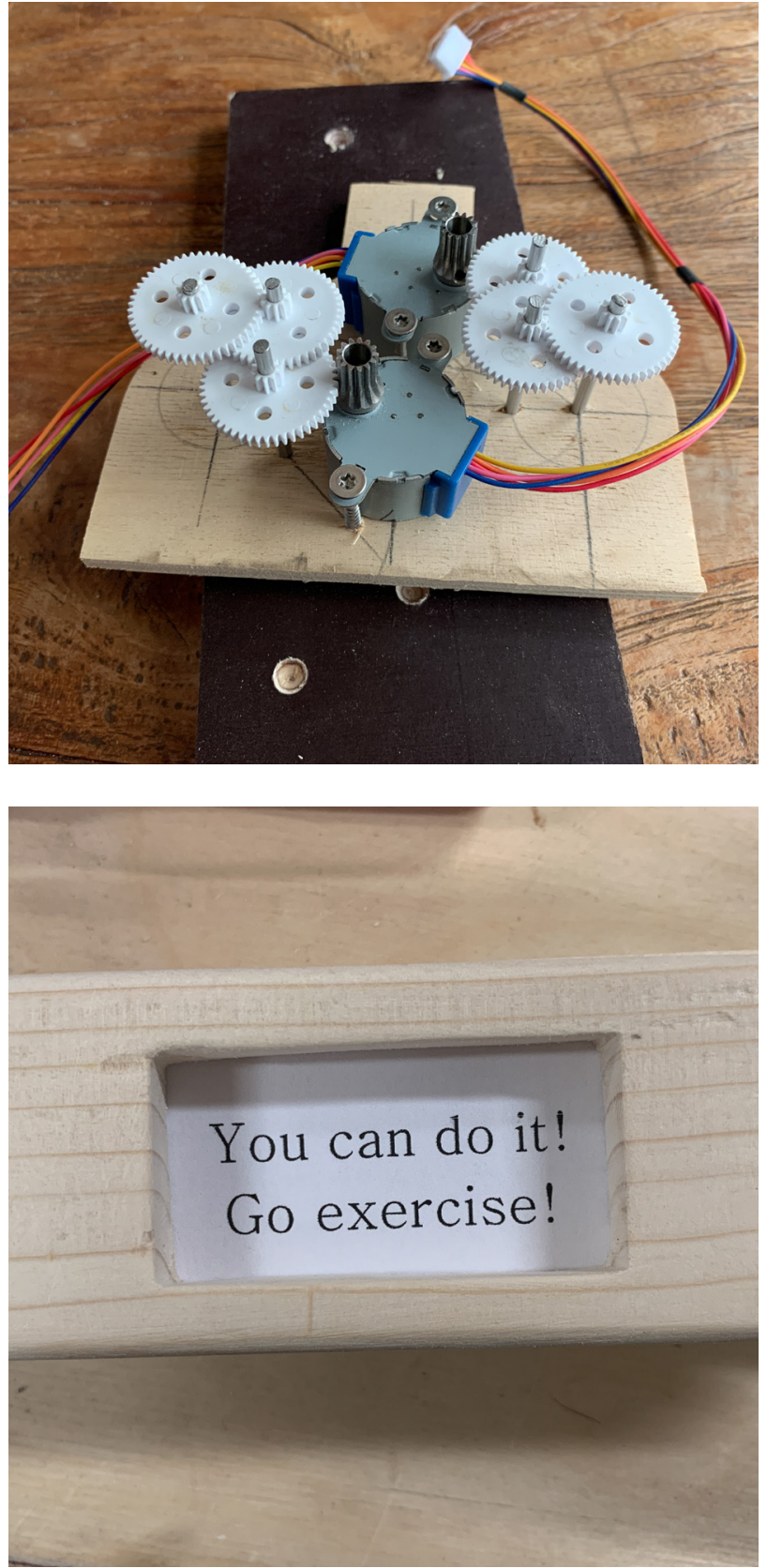

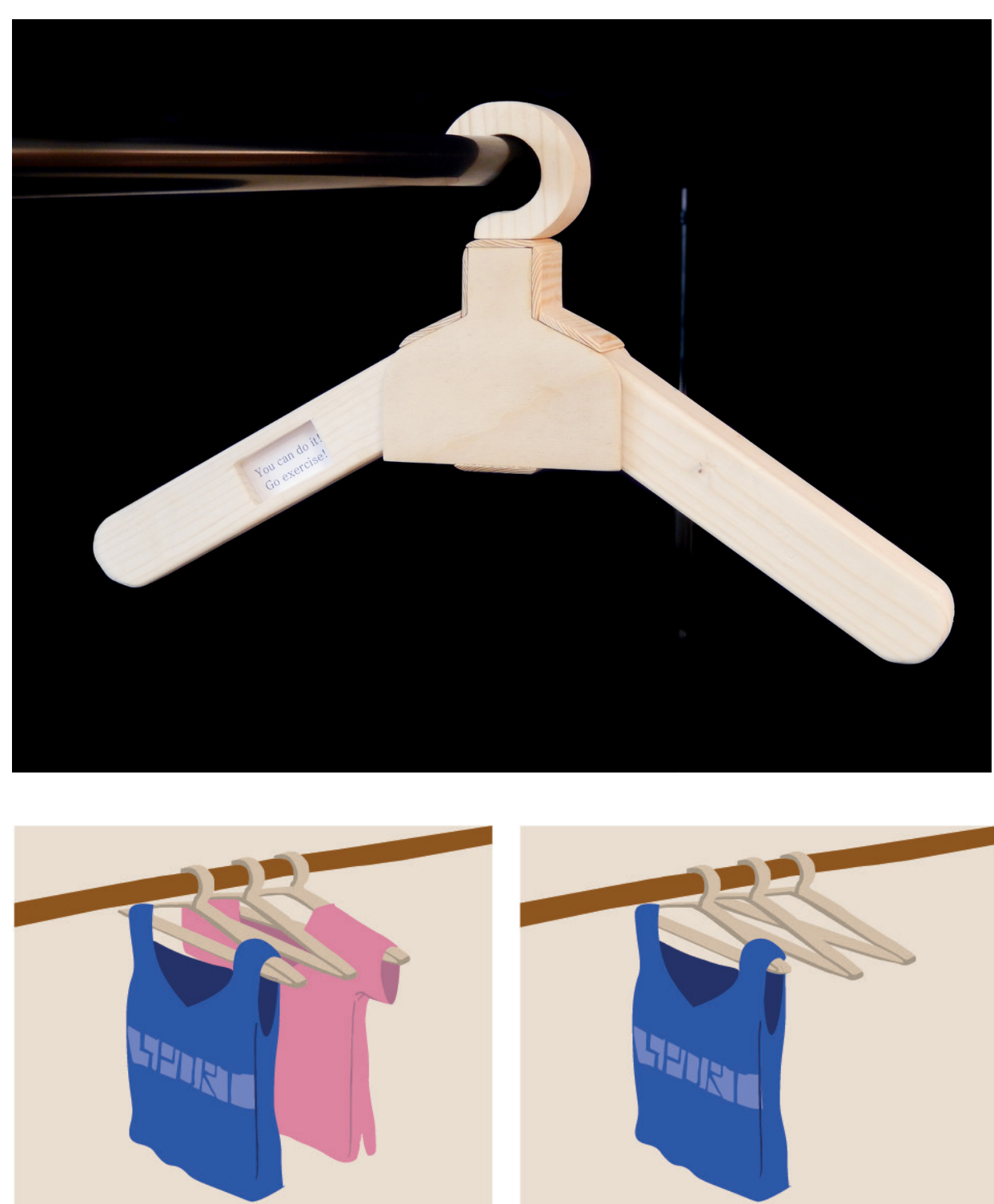

1. The clothing hanger detecs running intentions by hanging up your clothes

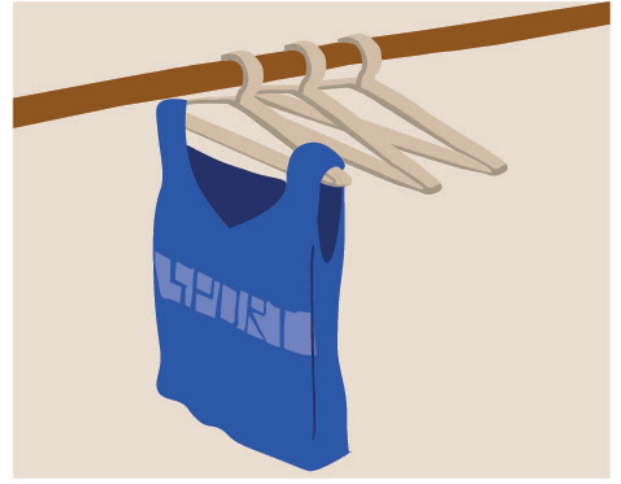

2. Over time, the hanger starts shrinking

\section{MERIA: A FRIENDLY TROUBLEMAKER}

Meria is a clothing hanger situated in the closet that dismisses clothes when one does not go exercising as intended. The user can hang their sports clothes, and according to their activity goals, the hanger will shrink in a few days, by lowering its arms. While this happens, Meria tries to encourage the user to grab their clothes and go exercise, by letting the clothes slip more and more. When the clothes are ignored for a period of time, the hanger will eventually drop the clothes on the ground. Although Meria does not make the choice to go exercising easier or harder (freedom), it gives the user the opportunity to reflect on their activity goals by being slightly annoying. The user would then have to collect their sport outfit from the ground and put them back on the hanger, creating friction, or can decide to cheat the system for instance by leaving them on the ground. While holding the clothes there might be even less of a barrier to actually go exercise. The hanger implies an alternative choice: if you are holding the clothes anyway, why not put them on and go exercise? If they take the clothes off the hanger and not ignore its signals, they will find an encouraging message hidden under the clothes.

Another scenario is to 'beat the hanger to it', by grabbing the clothes before they fall on the ground, and going for a workout. To try and increase the sense of enjoyment this might create, a motivational message was added on the hanger, positioned under the clothing. The user will only see this when they interact with the prototype, which might give them a final nudge towards getting dressed for the workout or at least encourage reflection when they decide to hang the clothes back [5].

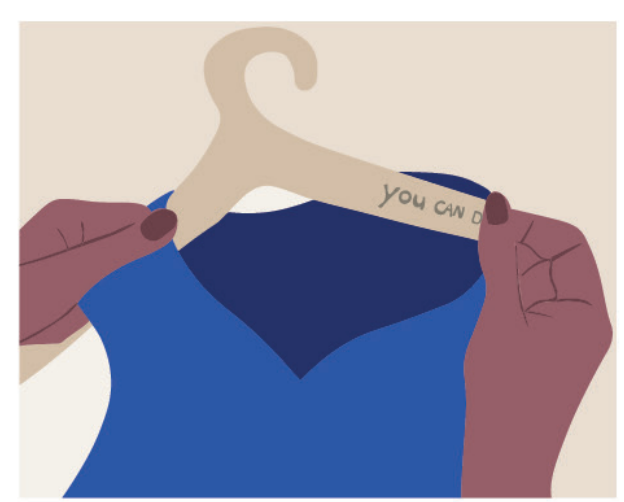

3. A motivational quote appears when you take the clothes off the hanger

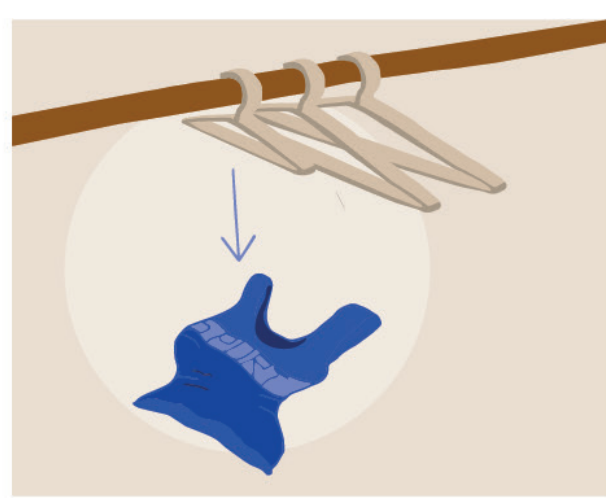

4. If you don't take the clothes off, the hanger throws the clothes on the ground 


\section{USER STUDY}

To investigate how the careful crafting of the aesthetics of the design Meria influences the acceptance of the friction, we conducted a 14-day field study with one participant. Our participant is a 26-year-old woman, who has the intention to work out twice a week to build stamina and get stronger, yet experiences motivational barriers. Meria is placed in the closet of the participant, and she is asked to hang her workout clothes on the hanger. The hanger was already set to her workout goals, of two times per week. We report on a semi-structured interview done after 14 days.

\section{Overall Experience}

"Actually [using the hanger was] a lot of fun. I didn't expect this, because usually I do like something new, something innovative, but it was also more fun than I thought."

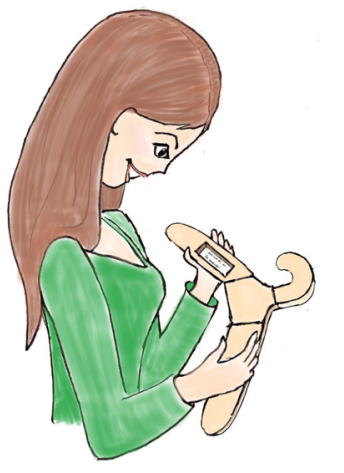

Betraying the System is Betraying Oneself?

"You really see it, which is motivating, but if you don't feel so good, then you feel extra guilty that you're not going. So this is both positive and slightly negative. If you see it, it feels like you're betraying it."

\section{Challenging the System}

"If you try often enough to not let it drop the shirt, then it is nice if you succeed."

\section{Aesthetics through Materiality}

"I really liked the hanger, it was sort of warm. Normally you would have a plastic hanger and its cold, but wood is more homey. It felt nice in my hands."

\section{Troublemaking as a Motivation Trigger} shirt of the hanger.' workout. So the right kind of annoying." your shirt up and go exercise."

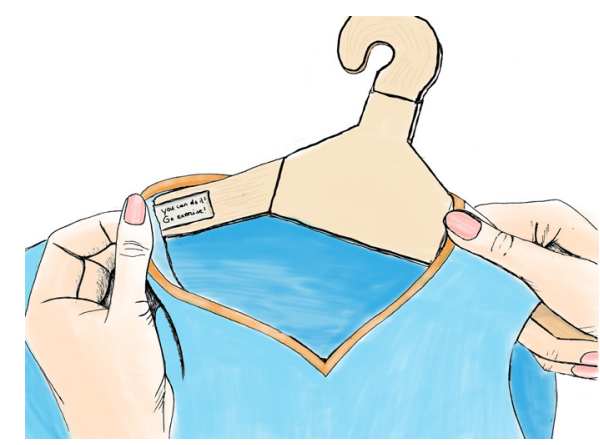

\section{Effect of the Rewarding Message}

"I knew that the encouraging text was in the hanger, but it was at the back. So I sort of forgot, and if I got the clothing off the hanger then I thought: Hey, there is also extra motivation, so that was really fun, that was nice."

"It's really nicely made in the wood, but it also was less visible. Maybe you could put lights next to it so it pops out more. Or if when you open the closet it reflects. If it is supposed to be a static text, then you could also make as a relief in the wood that you can also feel it."

"I want to do sports more, but I also noticed that when I got the shirt off the hanger, that I got extra motivation, and that I was bummed when I saw that the hanger had shrunk."

"I don't want my shirt to be on the ground. So I noticed that I started planning when I would work out next, when I got the

"It would be annoying, but not enough to be bloody annoying, but annoying enough to say: Okay, I will get my shirt and go

"In the moment when you see it laying on the ground you will think: Oh this is not fun. So that would be negative. But 2 seconds later you would get a positive motivation to just pick

\section{Limitations}

"If it is on a weekend day, then you can think: Oh I will go for a run, but if it's a moment that you can't do that it might be a little bit harder and annoying".

"My sport shirts are very soft, and I noticed that it got stuck a little bit. So when the clothing hanger would shrink, it would never fall off."
"Maybe not every time, but maybe every time you change the shirt [the text could change]. It doesn't matter if it is three different rotating texts or twenty five, as long as you get a new reminder of why you do it."

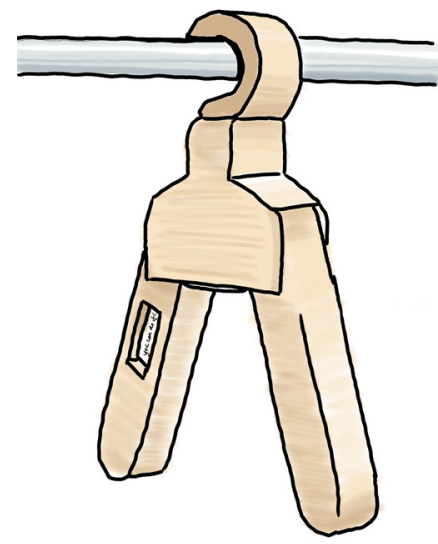

\section{Motor Sound as a Feedback Mechanisn}

"I thought, if you would have done a workout in the morning, that the hanger would be expanded by evening, but at the moment you got your clothing, you could hear the little machines doing their work. And then I thought: Ha! I'm doing well."

"If you have worked out faster than last time, then it would also make less sound. So that was an extra reminder: I have worked out a few times. So that was really nice. It was nice when the sound became shorter, but I have to admit that I liked it less when

"A few minutes is good [for the arms to go up]. If it would go very quickly then you would feel rushed to immediately hang a new shirt. And if it takes too long, for example a couple hours, then you would maybe forget to hang something new. Because you would think: Oh it's not ready yet."

"It was not very visible, so even though I did now it was going to happen, I thought: it is a sense of unease, thinking: I should really the sound became longer." 


\section{DISCUSSION}

This research builds upon the key elements of the Aesthetic of Friction as proposed by Hassenzahl and Laschke [5]. We designed Meria, a troublemaking clothing hanger that dismisses clothes when one does not go exercising as planned. Through our Researchthrough-Design process [27] we investigate how the careful consideration of the aesthetics of Meria influenced the acceptance of the implemented friction.

\section{Balance vs. Reward Based}

We used a scenario-based survey and product reaction cards to evaluate the envisioned experience of three scenarios. As opposed to a classical design process, we were not only looking for positive reactions from the target users but strived for a concept that triggered both positive and negative feelings. We aimed for 'friendly friction'. Yet simply reaching a balance in the number of chosen words between positive and negative ones is not enough, the nature and intensity of a specific emotion matters. For example, the word 'disgusting' was used by respondents to describe the Smelling Clothing, an experience described as 'disgusting' is unacceptable. Words such as 'frustrating' or 'annoying' have less negative connotation, and refer to several levels of intensity. Beyond the survey used in the present work, the same reasoning can be applied to other user research methods, considering both the valence but also the nature and intensity of the emotions triggered by an AoF artefact.

\section{Unanticipated Consequences}

The design of Meria intends to create friction once the clothes fall on the ground, and has a similar modality as Keymoment [14] and ReMind [12]. However, in Keymoment the keys fall instantaneous. The slow shrinking of Meria can be seen as an interface, just like ReMind. Yet, our user study showed that the hanger embodied a sense of 'time not spent exercising' rather than acting as a reminder for 'when to do the action' like ReMind. Although unintended, the slow shrinking of the hanger already was considered frictional, raising a feeling of uneasiness. This is in opposition to our intention of a non-intrusive artefact, and added an additional layer of friction that we did not intend to design for.

Although not designed as such, Emma felt enjoyment when she heard the arms going back up. Contrary to the shrinking of the hanger being silent (because of the slow speed), the hanger going to its original shape produced some sound. We designed the visual feedback of the arms gaining its original shape to spark a reflection moment. Hearing the arms, the phenomenon actually raised a feeling of enjoyment instead. This was however only the case when she was successful in being one step ahead of the hanger, by taking the clothes off and going for an exercise. Noteworthily, Emma experienced negative emotions when the sound was longer (i.e. the hanger needed more time to go back to its original shape), as this embodied the length of 'time not spent exercising'. The sound of the arms going up, could generate both positive and negative feelings, based on the context. Although we prototyped three iterations of the hanger, we did not anticipate, before deploying it to the field, the sound of the arms to be one of the aesthetical features encouraging enjoyment or creating friction.

\section{Designing the Entire Experience}

Through this pictorial, we illustrate that, while one can speculate and conceptualize AoF, it actually comes to life through the act of designing. This is of course the case for any designed artefact, but it is of a higher importance within AoF designs, which depend on a careful balance between friction and aesthetics. Every facet of the experience has an effect on that balance and might skew it undesirably to a tipping point where friction as a mechanism for change is not effective anymore. Adopting the AoF as a design approach, one should design the entire experience: from the first look of the design, the way the material feels, how the electronics interferes, to the design going back to its original state. As intended, the choice of material of Meria and its smooth properties were considered enjoyable. Careful and in-depth material explorations are key in the experience of AoF, as some might be at the core of positive feelings while others might cause unwanted side effects to the harmony of AoF.

Testing the experience of the design in context, and deploying it autonomously for several weeks or months is a final crucial element. The 'full state' of a design cannot be experienced entirely unless it is situated. A bottleneck might however be that (aesthetical) experiences are often personal and interindividual differences would impact the effect of friction. A challenge thus is to design for the entire experience but still leave room for open-ended interpretation and unexpected meaning-making.

\section{Avoiding Friction as a Goal}

Although AoF is a valuable perspective for exercise motivation design, a focus on goal orientation should be prevented. Goal orientation happens once getting the task done (e.g., beating the hanger), is becoming the main goal for the user instead of going for an exercise, which will result in outcome-based motivation [23]. Extrinsic controlled motives, although effective in many cases, are not believed to result in long term sustained behavior [25]. Since AoF design often elicits a sense of accomplishment when choosing the implied course of action, there is a higher risk of it becoming the goal in itself. Whether this negatively affects longterm sustained behavior needs further research.

\section{Limitations \& Future Work}

In this Research-through-Design process we chose to let one participant experience Meria over the course of 14 days, compared to a lab study involving a larger sample size. Since one of the key principles of AoF is its situatedness in the moment of choice, we chose this qualitative and explorative approach. Note that the goal of our field study was not to investigate intended behavior change caused by the novel system [9], but to gain in-depth insights in the careful process of designing for 'friendly friction'. Although getting dressed was highlighted as an important decision-making moment, 
our field study showed that the shrinking of Meria was not always visible during the moment of choice. The user could have a busy day of work ahead, and the hanger would still have shrunk, without them being able to take action. In this sense, Meria only functions as a reminder. Contextual insights are needed to understand whether friction is experienced differently (e.g., when someone notices the clothes falling in the moment vs. seeing them laying on the ground), to further improve the appropriate moment of choice and level of friction. Besides apps and activity trackers, product designs for exercising motivation are quite scarce. Published examples can be found in [17-19]. Most of these however rely on a form of nudging or reward. To understand the Aesthetic of Friction and its impact on exercising intention, more design work and documentation is needed in this area.

\section{CONCLUSION}

In this pictorial we report on our Research-throughDesign process in which we design Meria, a troublemaking clothing hanger that dismisses clothes when one does not go exercising as planned. Meria is designed with the key principles of the Aesthetic of Friction as proposed by Hassenzahl \& Laschke [5]. We investigate how the careful consideration of the aesthetics of Meria influenced the acceptance of the implemented friction. The main contributions to the HCI and design community, of this paper are (1) a demonstration of how to apply the design paradigm, Aesthetic of Friction, throughout all stages of the design process, and (2) insights into the role of friction in design and behavior change. Through this in-depth and reflective immersion in the design process of an AoF artefact, we provide insights to the design community interested in using fiction as a mechanism to nudge people into a specific behavior. This behavior is not limited to the topic of exercising, but might be interesting for other applications areas as well where behavior change is desired (e.g. sustainability, food intake).

\section{ACKNOWLEDGEMENTS}

The authors would like to thank the reviewers for their valuable comments and feedback improving the quality of the paper. We would also like to thank all the participants who contributed to this study. This work is part of the project Nano4Sports which is financed by Interreg Vlaanderen-Nederland.

\section{REFERENCES}

[1] Joey Benedek and Trish Miner. 2002. Measuring Desirability: New Methods for Evaluating Desirability in a Usability Lab Setting. Proc. UPA 2002: 5.

[2] Ana Caraban, Evangelos Karapanos, Daniel Gonçalves, and Pedro Campos. 2019. 23 Ways to Nudge: A review of technology-mediated nudging in humancomputer interaction. Conference on Human Factors in Computing Systems - Proceedings: 1-15. https:// doi.org/10.1145/3290605.3300733

3] Olafur Eliasson. 2020. Room for One Colour. https:// olafureliasson.net/archive/artwork/ WEK101676/ room-for-one-colour.

[4] Peter M. Gollwitzer. 1999. Implementation intentions: Strong effects of simple plans. American Psychologist 54, 7: 493-503. https://doi.org/10.1037/0003 066X.54.7.493

[5] Marc Hassenzahl and Matthias Laschke. 2014. Pleasurable Troublemakers. In The gameful world: Approaches, issues, applications, Steffen P Walz and Sebastian Deterding (eds.). Mit Press, 165-167.

[6] Johannes Jessen and Matthias Laschke. 2014. Intervator. http://www.pleasurabletrouble- makers.com/\#/ intervator/.

[7] Anne Marie Kanstrup and Pernille Bertelsen. 2016. Bringing new voices to design of exercise technology: Participatory design with vulnerable young adults. ACM International Conference Proceeding Series 1: 121-130. https://doi.org/10.1145/2940299.2940305

[8] Flavius Kehr, Marc Hassenzahl, Matthias Laschke, and Sarah Diefenbach. 2012. A transformational product to improve self-control strength: the chocolate ma- chine. In Proceedings of the SIGCHI Conference on Human Factors in Computing Systems, 689-694.

[9] Predrag Klasnja, Sunny Consolvo, and Wanda Pratt. 2011. How to Evaluate Technologies for Health Behavior Change in HCI Research. In Proceedings of CHI 2011, May 7-12, 2011, Vancouver, BC, Canada., 3063-3072.

[10] Matthias Laschke, Sarah Diefenbach, and Marc Hassenzahl. 2015. "Annoying, but in a nice way": An inquiry into the experience of frictional feedback. International Journal of Design 9, 2: 129-140.

[11] Matthias Laschke and Marc Hassenzahl. 2021. The Aesthetic of Interaction. http://www. pleasurabletroublemakers.com/\#/aesthetic-of-frcition/.

[12] Matthias Laschke, Marc Hassenzahl, Jan Brechmann, Eva Lenz, and Marion Digel. 2013. Overcoming procrastination with ReMind. In In Proceedings of the 6th International Conference on Designing Pleasurable Products and Interfaces, 77. https://doi. org $/ 10.1145 / 2513506.2513515$

[13] Matthias Laschke, Marc Hassenzahl, and Sarah Diefenbach. 2011. Things with attitude: transformational products. In Create11.

[14] Matthias Laschke, Marc Hassenzahl, Sarah Diefenbach, and Thies Schneider. 2014. Keymoment: Initiating behavior change through friendly friction. In Proceedings of the NordiCHI 2014: The 8th Nordic Conference on Human-Computer Interaction: Fun, Fast, Foundational, 853-858. https://doi. org/10.1145/2639189.2670179

[15] Leib Litman, Zohn Rosen, David Spierer, Sarah Weinberger-Litman, Akiva Goldschein, and Jonathan Robinson. 2015. Mobile exercise apps and increased leisure time exercise activity: A moderated mediation analysis of the role of self-efficacy and barriers. Journal of Medical Internet Research 17, 8. https://doi. org/10.2196/jmir.4142

[16] Iris Van der Meiden, Herman Kok, and Gerben Van der Velde. 2019. Nudging physical activity in offices. 
Journal of Facilities Management 17, 4: 317-330. https://doi.org/10.1108/JFM-10-2018-0063

[17] Daphne Menheere, Mathias Funk, Erik Van Der Spek, Carine Lallemand, and Steven Vos. 2020. A Diary

Study on the Exercise Intention-Behaviour Gap :

Implications for the Design of Interactive Products. In DRS 2020 - in Proceedings of Desgin Research Society 2020. https://doi.org/10.21606/drs.2020.329

[18] Daphne Menheere, Evianne van Hartingsveldt, Mads Birkebæk, Steven Vos, and Carine Lallemand. 2021. Laina: Dynamic Data Physicalization for Slow Exercising Feedback. In DIS '21, June 28-July 2, 2021, Virtual Event, USA, 26. https://doi. org $/ 10.1145 / 3461778.3462041$

[19] Daphne Menheere, Carine Lallemand, Ilse Faber Bram Monkel, Stella Xu, Jesse Pepping, and Steven Vos. 2019. Graceful interactions and social support as motivational design strategies to encourage women in exercising. In In Proceedings of the Halfway to the Future Symposium, 1-10. https://doi. org/10.1145/3363384.3363404

[20] Daphne Menheere, Carine Lallemand, Erik van der Spek, Carl Megens, Andrew Vande Moere, Mathias Funk, and Steven Vos. 2020. The Runner's Journey: Identifying Design Opportunities for Running Motivation Technology. In Proceedings of NordiCHI'20.

[21] Florian Floyd Mueller, Chek Tien Tan, Rich Byrne, and Matt Jones. 2017. 13 Game Lenses for Designing Diverse Interactive Jogging Systems. In Proceedings of the Annual Symposium on Computer-Human Interaction in Play, 43-56.

[22] Paschal Sheeran and Thomas L. Webb. 2016. The Intention-Behavior Gap. Social and Personality Psychology Compass 10, 9: 503-518. https://doi. org/10.1111/spc3.12265

[23] Maferima Touré-Tillery and Ayelet Fishbach. 2014 How to Measure Motivation: A Guide for the Experimental Social Psychologist. Social and Personality Psychology Compass 8, 7: 328-341. https://doi. org/10.1111/spc3.12110
24] Ivo Vlaev, Dominic King, Paul Dolan, and Ara Darzi. 2016. The Theory and Practice of "Nudging": Changing Health Behaviors. Public Administration Review 76, 4: 550-561. https://doi.org/10.1111/puar.12564

[25] Philip M Wilson, Diane E Mack, and Kimberly P Grattan. 2008. Understanding motivation for exercise: a self-determination theory perspective. Canadian Psychology/Psychologie canadienne 49, 3: 250.

[26] Haian Xue and Pieter M.A. Desmet. 2019. Researcher introspection for experience-driven design research. Design Studies 63: 37-64. https://doi.org/10.1016/j. destud.2019.03.00

[27] John Zimmerman, Jodi Forlizzi, and Shelley Evenson. 2007. Research through design as a method for interaction design research in HCI. Conference on Human Factors in Computing Systems - Proceedings: 493-502. https://doi.org/10.1145/1240624.1240704 